\title{
AUTOMATION OF CONTROL OF THE BUSINESS PROCESS OF PUBLISHING SCIENTIFIC JOURNALS
}

\author{
Sakaliuk O.Yu. ${ }^{1}$ \\ ${ }^{1}$ Odessa National Academy of Food Technologies, Odesa \\ E-mail: ${ }^{1}$ sakaliuk.olexiy@gmail.com
}

Copyright (C 2014 by author and the journal “Automation technological and business - processes". This work is licensed under the Creative Commons Attribution International License (CC BY). http://creativecommons.org/licenses/by/4.0/

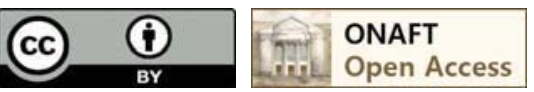

\begin{abstract}
We consider business process automation publishing scientific journals. It describes the focal point of publishing houses Odessa National Academy of Food Technology and the automation of business processes. A complex business process models publishing scientific journals. Analyzed organizational structure of Coordinating Centre of Scientific Journals' Publishing ONAFT structure and created its model. A process model simulation conducted business process notation eEPC and BPMN. Also held database design, creation of file structure and create AIS interface. Implemented interaction with the webcam. Justification feasibility of software development, and the definition of performance based on the results petal chart, it is safe to say that an automated way to much more efficient compared to manual mode. The developed software will accelerate the development of scientific periodicals ONAFT, which in turn improve the academy ratings at the global level, improve its image and credibility.
\end{abstract}

Keywords

Business process, process model, BPMN notation, automated information system, webcam, social impact development.

Introduction

Today, more enterprise managers are considering the use of information technology as an opportunity to improve the efficiency of the business process. Operational control of the company's activities, performance and attitude of each employees to ensure accelerated growth in the development process, the ability to effectively expand personnel. An important advantage of the automation system is high speed. A qualified employee to spend full time on assembling a complex report and program generated in seconds Automation system provides a manager full and accurate information necessary to adequately assess the current situation and timely decision making. Automation system provides secure storage of all information. Each employee works only with data available to him under the hierarchy levels in the company. Verification of user access program implemented, attempts of unauthorized access to information recorded automatically.

Recently there is a tendency to develop information systems based on database management systems (DBMS), which contain relevant data libraries and core software, that a particular algorithm provides access depending on user rights and tasks that lie ahead.

There are various information systems that provide management staff. Particularly, there is software «Evernote» to create and store notes [1]. There is also an organizer for personal use and teamwork «LeaderTask» [2]. But these programs do not completely solve this problem, standing in the automation of business process publishing scientific journals, therefore it was decided to develop its automated information system, that would meet the needs of employees coordination center of the publishing.

The growth requirements scientists XXI century has meant that their research papers to be published in recognized, modern and authoritative editions. The list of requirements put forward to scientific publications is almost endless, but there are still a number of comments, a decision which will raise the level of scientific publications in the world ranking. Particularly, the availability of a web-site of the scientific journal; publication articles that written exclusively in English; the timely release of the scientific journal; numerical measure of the importance of the scientific journal (Impact Factor), and more. Since the requirements put forward in scientific periodicals need to focus on studying the subject, qualification in the 
field and systematization of acquired skills - logical creation of centers that coordinate and assist in the promotion and publication of scientific periodicals.

Odessa National Academy of Food Technologies today is not only a place to gain knowledge of students, but also a factor of science as such. The development of scientific schools always due to the need of research publications. For this purpose, at the Odessa National Academy of Food Technologies was founded 9 of periodic scientific and industrial publications.

Questions and of publishing house of periodicals engaged in the relevant department. Different approach to management in the publishing of magazines inevitably leads to disproportional to their development..

For the organization of equal development of all periodicals Odessa National Academy of Food Technology and bring them to international standards publishing scientific periodicals in early 2014 was based Coordinating Centre of Scientific Journals' Publishing.

Coordinating Centre of Scientific Journals' Publishing does not produce products and provide services for authors and users of scientific publications on pre- and post- Publication support publishers.

At this stage of computerization in all spheres of human life is very acute question of automation management.

The automated system of enterprise management (ASEM) - a set of software, technical, information, linguistic, organizational and technological means and qualified personnel actions designed to meet the challenges of planning and management of various types of enterprises.

Automated control systems now required to optimize and improve the efficiency of management and certain other personnel services company. Experts say that business management through automated systems contributes to the competitiveness of any company.

Automating business processes - all that helps:

- manually get rid of routine, repetitive operations;

- increase the speed of processing and transmission of information;

- create a single information space for individual departments or the enterprise as a whole.

The result will automate quality, systemic change in business in force:

- programmed automatic reception of documents, reports, summaries;

- improve the quality of databases - the accuracy, completeness, speed, consistency;

- bring departments or the entire enterprise in a single set of associated daily workflow and standardized information and regulatory framework.

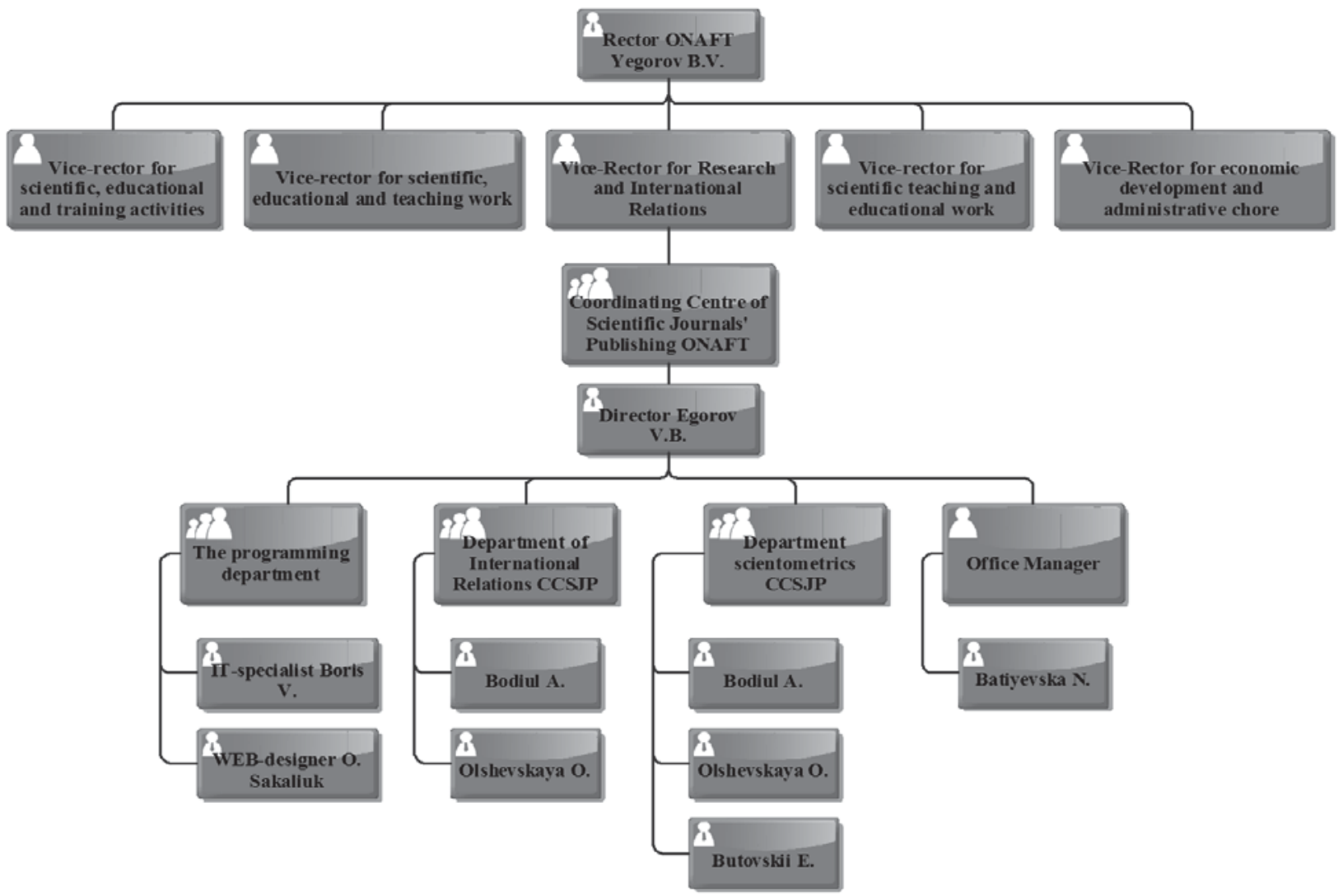

Fig.1 - Model organizational structure of Coordinating Centre of Scientific Journals' Publishing ONAFT 
The organizational structure of Coordinating Centre of Scientific Journals' Publishing ONAFT is the pivot that allows better allocate responsibility and authority within the organization. Therefore, improvement and analysis of organizational structure is one of the constituent phases of business modeling. What is the optimal organizational structure of the company? Obviously, this is the organizational structure that allows to realize the goals and perform necessary tasks (services) with sufficient efficiency (at the scheduled time, in the right quantity, etc.). Having built business processes and dividing responsibility for the functions performed, we can calculate the load for each position or calculate labor costs for the execution of business processes.

The organizational structure of the company like the Egyptian pyramids, which are at the heart of subordinate employees, and on top - the head of the company.

Business Process publishing of scientific journals - a sequence of work performed by workers Coordinating Centre of Scientific Journals' Publishing ONAFT and for certain technology and using the technical, media, converts the input stream (articles not ready for publication) with input parameters, the output stream (article ready for publication), with other parameters that represent value to the consumer. Business process scientific journals publishing process consists of the following under process model is shown in Fig.2:

- support publishers in publishing (prepress, design, execution, assigning DOI numbers; bringing lists of references to articles according to accepted style design);

- register and download metadata material published in leading abstracts database;

- registration and indexing global index system;

- maintenance of websites relevant journals;

- support arithmetic mean index of citing scientists.

Table 1 - Inputs and outputs of each subprocess

\begin{tabular}{|c|c|c|}
\hline Name subprocess & Input & Output \\
\hline $\begin{array}{ccc}\text { support } & \text { publishers } & \text { before } \\
\text { publications } & & \end{array}$ & $\begin{array}{l}\text { Article not prepared for } \\
\text { printing. }\end{array}$ & $\begin{array}{l}\text { Article trained for publication } \\
\text { with DOI number. }\end{array}$ \\
\hline $\begin{array}{l}\text { register and download metadata } \\
\text { material published in leading abstracts } \\
\text { database }\end{array}$ & $\begin{array}{l}\text { Not registered in the journal } \\
\text { abstract database metadata and } \\
\text { not loaded. }\end{array}$ & $\begin{array}{l}\text { Bibliographic database with } \\
\text { metadata journal articles. }\end{array}$ \\
\hline $\begin{array}{l}\text { registration and indexing systems } \\
\text { world index }\end{array}$ & $\begin{array}{l}\text { Not registered journal in the } \\
\text { index system and the } \\
\text { article/magazines } \\
\text { indexes. }\end{array}$ & $\begin{array}{l}\text { Joined journal in the index } \\
\text { system of assigned indexes. }\end{array}$ \\
\hline $\begin{array}{l}\text { support and maintenance of Internet } \\
\text { sites relevant journals }\end{array}$ & $\begin{array}{l}\text { WEB-site, where the } \\
\text { information is not updated. }\end{array}$ & $\begin{array}{l}\text { WEB-site with updated } \\
\text { information. }\end{array}$ \\
\hline $\begin{array}{l}\text { support arithmetic mean index of } \\
\text { citing scientists }\end{array}$ & $\begin{array}{l}\text { The scientist, is no citation } \\
\text { index. }\end{array}$ & A scientist has index citation. \\
\hline
\end{tabular}

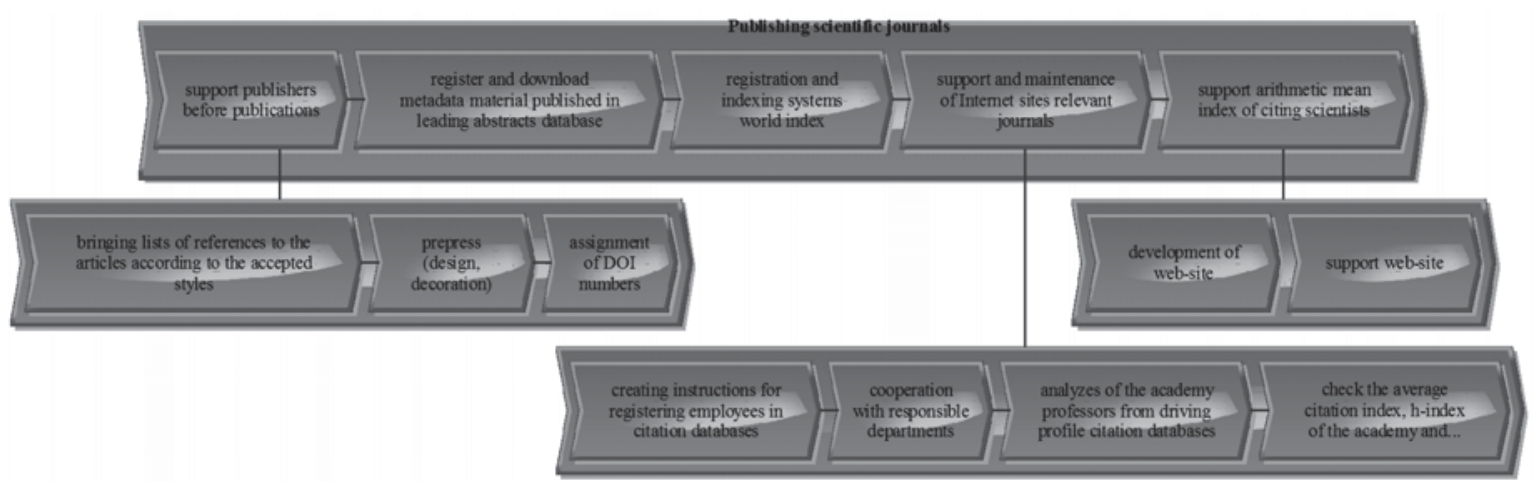

Fig. 2 - Process model business process "Publishing scientific journals" 
Modeling business processes - formal, made according to certain rules description action sequences professionals in the form of logical flow charts that determine the choice of further action based on situational fact. In the business process model sequence of individual actions together with appropriate procedures and scripts business processes. Describes interaction specialists from different departments within a business process.

The main advantage of the idea of analyzing business processes by creating the model - its universality. First, business process modeling - is the answer to almost all questions relating to the improvement of the company and increase its competitiveness. Second, the manager or management company that introduced at specific methodology will have information that will improve their own company and to predict its future.

People doing business, it is easy to work with business processes, displayed in the form of block diagrams. Many business analysts project and describe business processes using simple diagrams in BPMN notation, notation language so clear even at the user level. The main purpose of BPMN is to provide affordable notation describing business processes of all users, from the analysts that create circuit processes and developers responsible for implementing technologies fulfillment business processes to managers and ordinary users who run these business processes and monitor their implementation. Thus, BPMN is aimed at removing differences between the models of business processes and their implementation.

Elected members these interactions, director responsible for the average citation index, programmers, department of cooperation with international index systems. In order to determine the objectives of each party should be clearly create a picture of the loan process from start to finish, with all the nuances of emerging and conditions. That is, to know what happens in the performance or non-fulfillment of any conditions that further actions are performed, how they relate to other participants.

Information about the quality of services, as well as the process goes to the head CCSJP that analyzes and processes the information. Further, in a report, it sends its collective society headed by the rector and others (chief editors, heads of departments). Thus on the basis of this report, he makes corrective and control actions for improvement. Information about user satisfaction goes to the editor, who studied it exercises its control actions.

The owner of the business process - official approved by the company's management, which has the resources and information needed to perform business process. The owner has the responsibility for managing business processes and is responsible for its results and effectiveness, that it is in our case CCSJP staff, its main task - to perform work for the support and development of scientific periodicals.

Supervisors - the official who plans and is responsible for the performance of network processes or parts of it, is the analysis of the results and makes management decisions to maximize performance, it stands head CCSJP, its main task - to exercise control and corrective actions necessary to improve the performance and efficiency of the process.

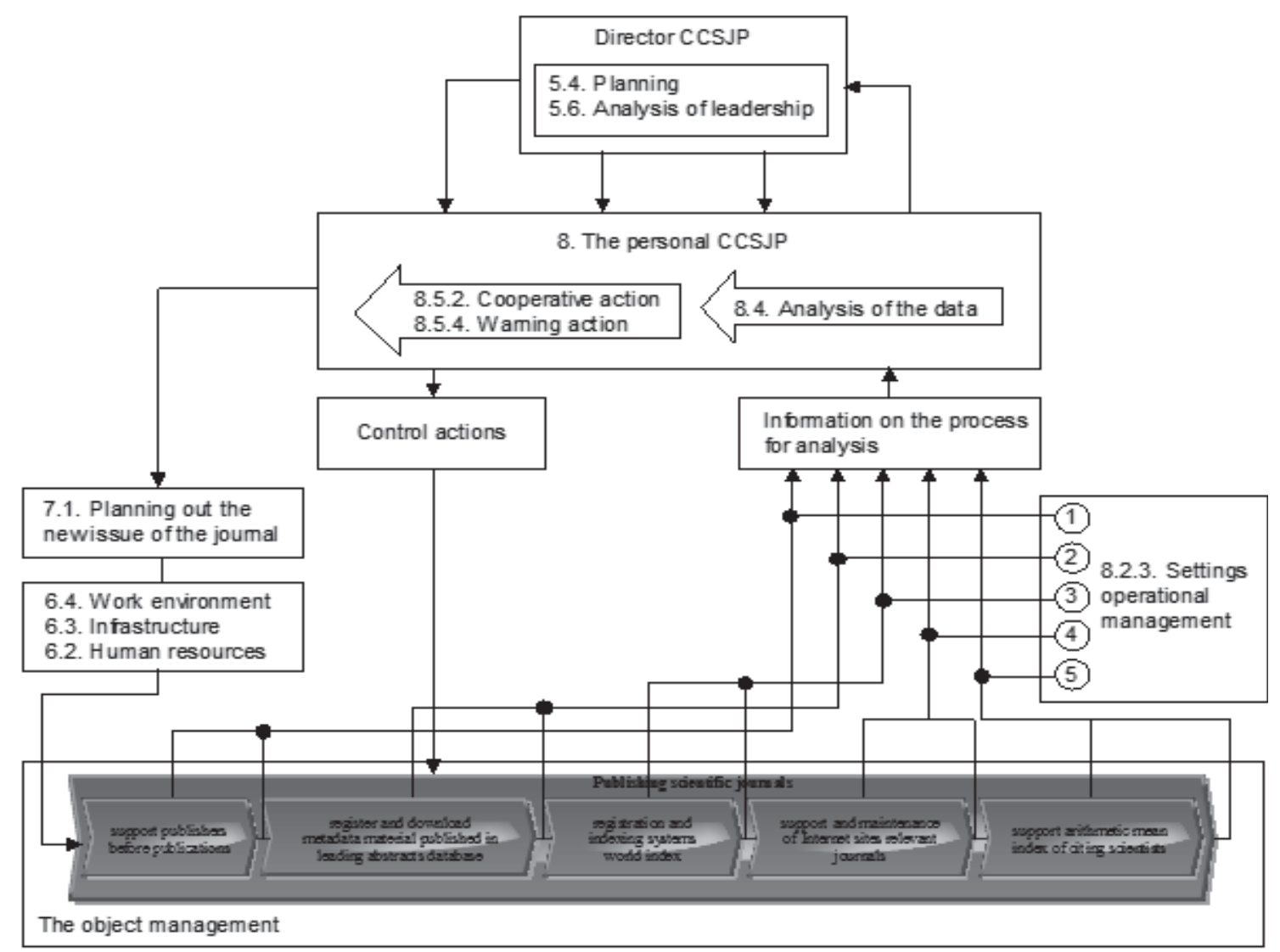

Fig. 3 - A conceptual diagram of the business process management "Publishing scientific journals" 
The best known is the concept of managerial process approach. "Process management approach" - implies that the object management system presented subprocesses, and management is carried out by deviations from the set values of these processes.

After analyzing the work of the owner and supervisors, determine control actions follows:

- CCSJP staff, checks the correct spelling of the references, design magazine assignment DOI indexes and international index of discharging abstract metadata in the database, monitors and analyzes the h-index;

- head CCSJP, analyzes the data results of the business process as a whole, makes corrective action subprocesses.

Numbers and names of elements cycle management process are given in terms of ISO 9000: 2000.

The interaction between the senior manager and owner of the process is as follows - the process owner receives targets from senior manager. Owner process periodically (reporting period - day, week, month, quarter, year) reports to the supreme leader on the process, offers designs of corrective and preventive actions appropriate to the process.

We can say that business process modeling allows to analyze not only how the company as a whole as it interacts with external organizations, customers and suppliers, but also as an organized activity for each individual job.

After the business modeling phase begins designing and developing automated information system. One of the first steps is to design a database model.

Stage design database is one of the most difficult stages of the creation of the database, which has explicit start and end. Compared with the analysis of requirements for elaboration or database applications, database design, according to many leading experts, is poorly structured task. If all the steps of creating a database overlap each other in their sequence, the design phase is covered with all the other stages.

Stage model development begins with building information model in various symbolic forms that are in the final stages embodied in a computer model. Information model is usually represented in some form of the sign. Table - one example of iconic models.

Define the table, which will form the data model. Thus for each table should answer three questions:

1. To collect, the information need this table?

2. Who should fill it?

3. What is the main purpose of its use?

The data model created should give an idea of how the database will look to developed software, of which tables it will contain which fields will contain tables, etc.

In drives using information stored files. The unique file name provided that the full file name for the actual filename considered together with the way of access to it. The road access to the file begins with the name of the device and includes all the names of directories (folders) through which passes. Successful filenames can greatly facilitate the user experience, helping to navigate a large amount of various information posted on the disks. But for intensive use PC file number is increasing, and follow the ordering information on the disk becomes increasingly difficult. To organize disk space used directories. As used separator character "I" (backslash - backslash limit).

All files are in the software hosting platform. Access to files can be accessed through the file manager via FTP.

When drafting the special attention required interface. Design software and high-quality design - a measure of the company's image, the expression of its relationship to potential customers. If the product looks nice and original, then its owner it is important to make a good impression on visitors, and he is interested in your attention and evaluation.

Using modern technology to create high-quality program, accurately and beautifully designed and pleasing to the eye. As for the basics, it is important to consider the weight of image files, since the high-weight graphic page will be loaded for a long time and adversely affect the performance of employees.

Also, when you make important design the right combination of colors follow the color balance, well-chosen proportions, lighting and volume graphics. The design of the program should be developed based themes and objectives of the operation web resource.

Smart layout - the key to success when working with the program, because the nice and easy program to work more satisfying than the program poorly designed. During the work I used block layout. Use logical markup. Software layout rigidly fixed, ie the width blocks set in px fixed.

As in any other AIS person interacts with the program through a number of interfaces, which she enters some data. In AIS "CCSJP Manager» there are some basic interfaces:

- authorization;

- registration;

- password recovery;

- authorized officer.

The advantage of my software products over others in the first place is that it adapts to every type of user individually, each has a personal interface features that are specific to a particular employee, ie extra functions relating colleagues excluded.

Implementation of developed automated information system will allow the provision of services:

- reduce the performance of tasks:

- reduce errors;

- improve the quality of work, a large flow of information collected can not always keep all remember. 
So you can better optimize the process of publishing scientific journals ONAFT. Reducing the time spent on service delivery editors of scientific journals ONAFT will enable scientific journals more quickly achieve high rankings and gain prestige in the world market.

After determining the effectiveness, comparing manual and automated way of working, the software obtained the following results.

Selected scale efficiency:

1) $\mathrm{No}-0$

2) Less -1

3) Few -2

4) Average - 3

5) Many - 4

6) More -5

Choosing criteria for comparing options and calculations appreciate the help given quantitative characteristics:

Table 2 - Determination of efficiency

\begin{tabular}{|c|c|c|}
\hline Criteria & Automated method & Manual mode \\
\hline Reducing complexity & 4 & 2 \\
\hline Reduced monotony & 3 & 2 \\
\hline Ergonomics & 5 & 3 \\
\hline Safety & 5 & 4 \\
\hline
\end{tabular}

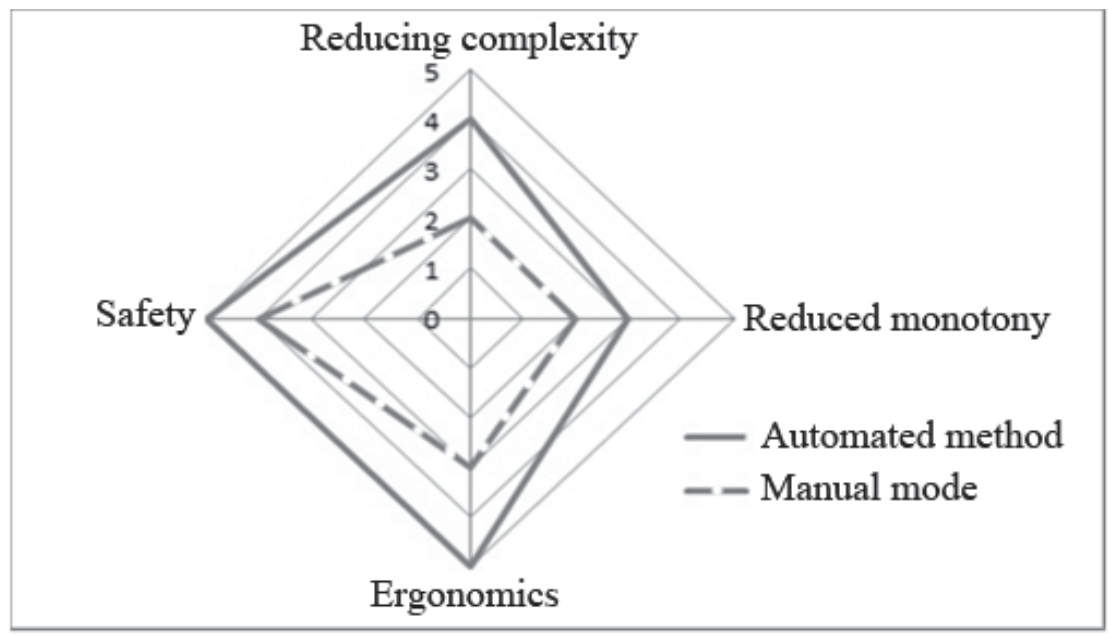

Fig. 4 - Chart definition of efficiency

Based on Radar Chart determination of efficiency, we see that an automated way to much more efficient compared to manual mode.

\section{Conclusion}

In the course for Coordinating Centre of Scientific Journals' Publishing ONAFT was developed AIS "CCSJP Manager». The software tool is convenient and easy to use. Employees have the ability to communicate, receive and assign tasks, organize meetings, work with reminders. Director CCSJP has the ability to monitor the flow of process and employment of staff. The main advantage over other similar programs is that it is personalized for each employee that is more convenient and this is one of the key factors in improving the efficiency of the staff.

Based on these "Charts determine effectiveness" can draw the following conclusion that an automated way to work much more efficient than the manual method in service editors of scientific publications. The developed software will accelerate the development of scientific periodicals ONAFT, which in turn will improve the ratings of the Academy at the world level and improve its image and credibility.

Currently the software works and staff CCSJP use it, but still have work to do. For full automation of business process would be appropriate to create an automated workflow and forecasting for the development of scientific publications.

\section{Reference}

[1] Sohranyayte myisli i idei | Evernote. - www.URL: https://evernote.com/intl/ru/ 
[2] Organayzer LeaderTask | Planirovschik | Elektronnyiy ezhednevnik | Spisok del | Napominalka. - www.URL: http://www.leadertask.ru/

[3] V. B. Egorov, "Naukonetriya kak aspect kar'eri uchenogo," Zhurnal «Ekonomika harchovoi promislovosti», vol. 25, no. 1, pp. 77-80, Mar, 2015

[4] Shiryaev, V.I. Upravlenie biznes-protsessami: ucheb.-metod. posobie / V.I. Shiryaev. - M.: FiS, INFRA-M, 2009. - 464 c.

[5] Sistemyi menedzhmenta kachestva - Osnovnyie polozheniya i slovar, ISO 9000:2000

[6] Sistemyi menedzhmenta kachestva - Trebovaniya, ISO 9001:2000

\section{[9] AUTOMATION NEWS}

\section{"Swarm" of tiny microrobots can carry out complex challenges through joint efforts}

Creation of the robots moving and operating like living people, is rather complex challenge. It is much simpler to create the robots operating like insects. If you happened to see a bee swarm or a high ant hill, then you know that through joint efforts these tiny creations can pull up trees literally. So why not to make something similar by means of group of tiny robots?

Researchers from Stanford University, the Parisian universities Universite Paris-Sud and Universite Paris-Saclay created "swarm" of the elementary microrobots which received the name Zooids. Each of robots has couple of wheels, the

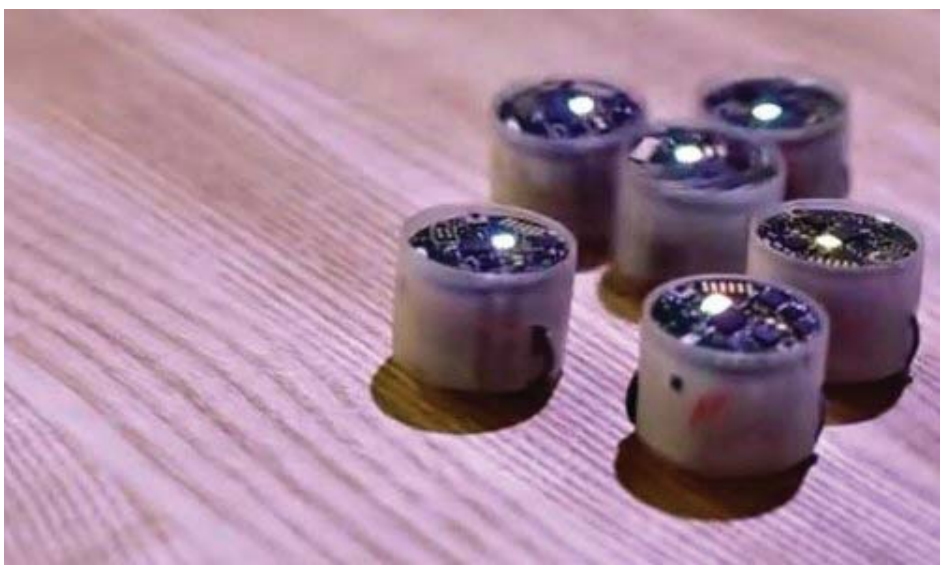
rechargeable battery, the touch sensor, a gyroscope, the optical sensor and the microcontroller. Capabilities of these microrobots are very far from capabilities of big ATLAS robots of the Boston Dynamics company, nevertheless, having united in group, they can carry out rather complex challenges.

Microrobots Zooids will hardly be able to be involved in military battles, however, as it is shown on the video given below, they can be used in the most unexpected scenarios. They can act as "pixels" of the improvised display, can drag to you your mobile phone and make many other things.

From the intellectual point of view it is possible to characterize robots Zooids with the term "full zero". But, by means of a specialized projector each of microrobots is capable to define and trace the location. Besides, the same projector can be used for transfer to robots of set of the instructions allowing them to carry out complex challenges through joint efforts .

Of course, robots Zooids can't be used in some purposes in practice. However, there will come that day when similar tiny devices "live" in your house in hundreds and in thousands. And it is going to be able for a big group of robots to cope not only with simple problems, cleaning of the room, for example, but also with heavier, for example, their joint efforts can become enough to move furniture according to your desire. 